\title{
Cannabinoids in models of chronic inflammatory conditions
}

\author{
Raphael Mechoulam ${ }^{1, *}$, Percy F. Sumariwalla ${ }^{2}$, Marc Feldmann ${ }^{2} \&$ Ruth Gallily ${ }^{3}$ \\ ${ }^{1}$ Hebrew University, Pharmacy School, Medical Faculty, Department of Medicinal Chemistry and Natural \\ Products, Jerusalem, 91120, Israel; ${ }^{2}$ Kennedy Institute of Rheumatology, Imperial College, London; ${ }^{3}$ The Lauten- \\ berg Center of General and Tumor Immunology, Medical Faculty, Hebrew University, Jerusalem, 91120, Israel; \\ *Author for correspondence (Tel: +972-2-6758634; E-mail:mechou@cc.huji.ac.il)
}

Key words: cannabidiol, HU-320, murine collagen-induced arthritis, rheumatoid arthritis, TNF- $\alpha$

\begin{abstract}
Cannabis sativa has been used as an anti-inflammatory plant for millennia. However until the elucidation of the chemistry of its constituents and the discovery of the endogenous cannabinoid system only a limited amount of research had been done on the effects of the plant or its constituents on inflammation. In the present overview we summarize our work on the effects of the non-psychotropic cannabidiol (CBD) and of a synthetic cannabidiol-derived acid (HU-320) in animal models of arthritis. Both compounds block progression of the disease, when administered after its onset. Cannabidiol was equally effective was administered i.p. or orally. Significant protection of the joints against severe damage was noted. In vitro cannabidiol reduced lymphocyte proliferation, and TNF- $\alpha$ formation and blocked zymosan-triggered production of reactive oxygen intermediates (ROI). Ex vivo lymph node cells from CBD-treated mice showed a decrease of collagen II-specific proliferation and IFN- $\gamma$ production. A decreased release of TNF by knee synovial cells was also noted. A synthetic cannabidiol derivative, HU-320 also inhibited production of TNF and ROI by mouse macrophages in vitro and suppressed in vivo rise in serum TNF following endotoxin challenge. HU-320 showed no activity in a standard assay for THC-type psychotropic effects. These results suggest that CBD and HU-320 hold promise as potential novel anti-inflammatory agents.
\end{abstract}

Abbreviations: 2-AG - 2-arachidonoylglycerol; CBD - cannabidiol; CIA - collagen-induced arthritis; CII collagen type II; IFN - interferon; IL - interleukin; LPS - lipopolysaccharide; NO - nitric oxide; ROI reactive oxygen intermediates; THC - tetrahydrocannabinol; TNF - tumor necrosis factor

\section{Introduction}

Cannabis sativa has been used as an anti-inflammatory plant for millennia. Evidence from populations with various cultural backgrounds is now available. Thus, Campbell Thompson (1949) has compiled an Assyrian herbal based on fragments of cuneiform plant lists and tablets, most of the era of Ashurbanipal (died 626 B.C.). Cannabis is mentioned as a drug used in numerous diseases. Its fumes were a drug for the 'poison of all limbs' - presumably arthritis. Centuries later Pliny the Elder mentions that the root boiled in water eases cramped joints as well as gout
(Brunner, 1973). Pedanius Dioscorides (died about 199 A.D.) in his famous Herbal, which was one of the basic books on drugs throughout the Middle Ages, mentions that cannabis roots dissolve edema and assuage inflammations (Dioscorides, 1934). In India cannabis was used both orally and as poultices applied over inflamed, painful parts of the body (Chopra and Chopra, 1957). The British physician O'Shaugnessy meticulously recorded the popular and medical uses of various cannabis preparations in India and later conducted animal and human experiments with them. $\mathrm{He}$ described the treatment of patients with a variety of diseases, chosen to confirm well established local 
traditions (O'Shaugnessy, 1843; Mechoulam, 1986). In the case of rheumatism two out of three cases were 'much relieved of their rheumatism; they were discharged quite cured in 3 days after.' The third patient' experienced no effect whatsoever, and on further inquiry it was found that 'he was habituated to the use of gunjah in the pipe.' This was an early report on tolerance, which was also found in a few other cases.

The reports by O'Shaugnessy were received in England with considerable interest and gradually Indian hemp became an accepted drug in therapy. Donovan (1845) reported that cannabis tincture made from Indian, but not from local cannabis (hemp), was highly effective in cases of neuralgic pain in the arms and fingers, inflammation of the knee and sciatica. In a mid-19th century review Christison (1851) concluded that cannabis tincture was particularly helpful in rheumatic pain. About 40 years later Queen Victoria's physician Russell Reynolds (1890) summarized his long clinical experience: '... Indian hemp when pure and administered carefully is one of the most valuable medicines we posses... ...In almost all painful maladies ... [it] was by far the most useful of drugs'. Looking back, these reports certainly indicate efficacy, but the varying levels of the then unknown active principle most probably prevented wide use of the drug.

Although occasional articles on the therapeutic potential of cannabis continued to be published for decades after the turn of the 20th century, its medical use slowly declined. There are two major reasons for this decline:

A. The active constituents of cannabis had not been isolated in pure form. Hence, crude plant preparations or extracts had to be used. Cannabis is notorious for its chemical variability and its easy deterioration. Therefore, reproducible clinical effects were not always obtained.

B. Legally, in many countries, cannabis was linked to the opiates. The use of these drugs was officially controlled and frequently made difficult. However, the opiates due to their medical indispensability continued to be widely employed; cannabis use declined.

Cannabis sativa and Papaver somniferum have been for a long time the source of the most widely used illegal drugs. However research on Cannabis sativa has always lagged behind that on Papaver somniferum. Thus, while morphine was isolated from opium early in the 19th century, tetrahydro- cannabinol (THC) was not fully identified until 1964 (Gaoni and Mechoulam, 1964); the first opiate receptors were described in the 1970s, but those of the cannabinoids were not discovered for another 20 years (Devane et al., 1988; Matsuda et al., 1990; Munro et al., 1993). The first endogenous opiates were isolated in the 1970s; the endocannabinoids in the 1990s (Devane et al., 1992; Mechoulam et al., 1995; Sugiura et al., 1995). Why the discrepancy? The reasons are mostly technical. Morphine forms numerous easily isolable, crystalline salts, while the active compounds in cannabis were known to be present in a complex oily mixture from which it was difficult to obtain pure constituents with the methods then available. In the 1930s and early 1940s Todd in the UK and Adams in the US reisolated cannabinol, which is probably an artifact and not an original natural product, and elucidated its structure (Todd, 1946; Adams 19411942). Cannabidiol (CBD), a constituent which showed no psychotropic activity in several animal assays, was also isolated, although its structure remained in doubt. However the constituent that causes the typical cannabis effects was not obtained in a pure form and could not be fully identified.

In the early 1960s we took a new look at the problem. By then better chromatographic techniques had evolved and we were able to separate numerous new cannabinoids - a term which we suggested then and which has received wide acceptance. First, we reisolated cannabidiol and obtained the psychotropic constituent $-\Delta^{9}-\mathrm{THC}-$ in pure form. Their structures were determined (Mechoulam and Shvo, 1963; Gaoni and Mechoulam, 1964). Some of the cannabinoids which were isolated by our and other groups during that period are presented in Figure 1. The structures and relative stereochemistry were elucidated by the then novel techniques of NMR and mass spectrometry. The absolute stereochemistry of $\Delta^{9}$-THC and of CBD and hence of all other cannabinoids with which they have been chemically related, was established by chemical correlation (Mechoulam and Gaoni, 1967).

About 70 cannabinoid-type constituents are known (Mechoulam, 1970; Turner et al., 1980). All of them are essentially variations on the structures represented in Figure 1. The chemistry, biochemistry, pharmacology and clinical effects of THC have been investigated in great detail (Mechoulam and Ben-Shabat, 1999). A considerable amount of 
<smiles>CCCCCCCCCCC=C(C)CCC=C(C)C</smiles>

Cannabigerol (CBG)

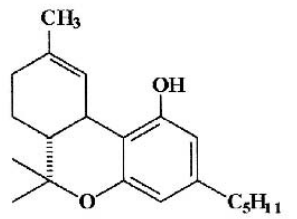

$\Delta$-tetrahydrocannabinol $\left(\Delta^{9}\right.$-THC)<smiles>CCCCCCCCCCCCCCCCCCCCCCCC</smiles>

Cannabichromene (CBC)

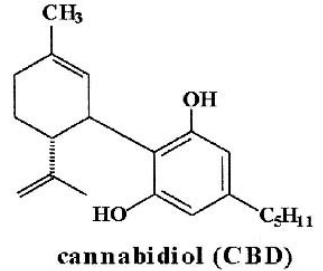

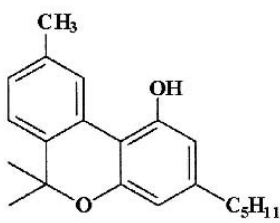

cannabinol $(\mathrm{CBN})$

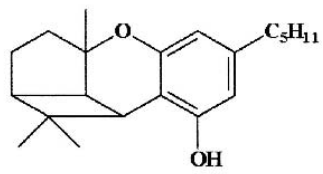

cannabicyclol (CBL)

Figure 1. Some plant cannabinoids.

work has also been reported on CBD (Mechoulam and Hanus, 2002; Mechoulam et al., 2002). However we still know very little about the rest of the constituents. Initially, for obvious reasons, most of the pharmacological work on the cannabinoids centered on the central nervous system (CNS), with emphasis on the psychotropic effects. Gradually reports covering other areas appeared. The present overview presents data on the effects of some cannabinoids in inflammation, with emphasis on those from our laboratories. For recent publications and general reviews on cannabinoids and the immune system and inflammation (Klein et al., 2003; Lambert et al., 2002; Melck et al., 2002; Roth et al., 2002; Cabral et al., 2001). Of particular interest and possible therapeutic importance of cannabinoids are the advances made in multiple sclerosis (Roth et al., 2002). This area is however beyond the scope of this overview.

For nearly 2 decades after the identification of $\Delta^{9}$-THC as the psychoactive constituent of cannabis, its mechanism of action remained an enigma. Initially it was assumed that cannabis action is somehow associated with membrane perturbation. However in 1984 Howlett, using a neuroblastoma cell line as a model system, demonstrated that cannabinoids interact with the adenylate cy-

clase second messenger pathway in an inhibitory fashion (Howlett and Fleming, 1984). The level of potency of a variety of cannabinoids to inhibit adenylate cyclase paralleled cannabinoid effects in animal models and in humans. Stereospecificity was also demonstrated using the HU-210 and HU-211 enantiomers (Howlett et al., 1990; Mechoulam et al., 1988). This line of research culminated in the discovery in the brain of specific, high affinity cannabinoid binding sites, whose distribution is consistent with the pharmacological properties of psychotropic cannabinoids (Devane et al., 1988). Shortly thereafter Matsuda et al. (1990) cloned this cannabinoid receptor which is now designated $\mathrm{CB}_{1}$. A peripheral receptor $\left(\mathrm{CB}_{2}\right)$ was identified in the spleen (Munro et al., 1993).

The existence of cannabinoid receptors suggested the presence of endogenous ligands. In order to look for such ligands, a specific, highly potent radiolabelled cannabinoid probe $\left[{ }^{3} \mathrm{H}\right] \mathrm{HU}-243$ was prepared (Devane et al., 1992b). Porcine brain fractions were found to compete with this probe for binding to cannabinoid receptors. Chromatography of such brain fractions led to the identification of a family of unsaturated fatty acid ethanolamides (Figure 2). The first active ligand isolated was arachidonoylethanolamide (anandamide) (Devane et al., 1992a). A second endocannabinoid - 2arachidonoyl glycerol (2-AG) was shortly thereafter identified in the periphery and in the brain (Mechoulam et al., 1995; Sugiura et al., 1995).

Structurally there is little in common between THC and the endocannabinoids. The plant cannabinoids are terpenophenols, while the endocannabinoids are fatty acid derivatives. Yet, pharmacologically they have much in common. Both THC and anandamide cause a typical tetrad of physiological effects: hypothermia, hypomotility, antinociception and catalepsy (Fride and Mechoulam, 1993). In most behavioral tests, anandamide and 2-AG are somewhat less potent than THC.

Recently evidence has been presented showing that additional cannabinoid receptors are present both in the CNS and in the periphery, but these claims have not been yet substantiated (Howlett et al., 2002).

\section{Some anti-inflammatory effects of cannabidiol}

Our present knowledge does not throw light on all cannabinoid actions. Thus cannabidiol, a major 


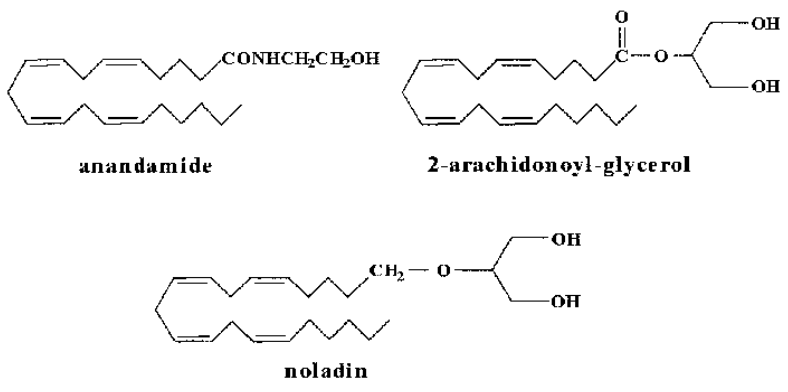

Figure 2. Endogenous cannabinoids.

plant constituent, which does not bind to either $\mathrm{CB}_{1}$ or $\mathrm{CB}_{2}$, has a plethora of pharmacological actions, but causes no THC-like psychotropic effects. However it is an anti-convulsive and antianxiety agent, both in animals and in humans. It has been reported to cause sleepiness and has recently been shown to prevent nausea in animal models. Its chemistry and pharmacological effects have recently been reviewed (Mechoulam and Hanus, 2002; Mechoulam et al., 2002). Its mechanism(s) of action are unknown, but it is quite possible that it binds to one or more of the putative cannabinoid receptors recently put forward (Howlett et al., 2002).

A few reports on the in vitro effects of $\mathrm{CBD}$ in immune systems have appeared. Watzl et al. (1991) reported that CBD reduced the levels of both tumor necrosis factor (TNF- $\alpha$ ) and IL-1 in human peripheral blood mononuclear cells. However concentrations of CBD, comparable to plasma levels found after smoking marijuana $(10-100 \mathrm{ng} / \mathrm{ml})$, increased the concentrations of IFN- $\gamma$; at higher concentrations (5-20 microgr $/ \mathrm{ml})$ a complete inhibition of the synthesis and/or release of this cytokine was observed. This biphasic effect is quite typical for cannabinoids (Sulcova et al., 1998). Srivastava et al. (1998) found that CBD strongly inhibited IL-10 production by a human leukemic $\mathrm{T}$ cell line. An earlier report indicated that CBD antagonized tetradecanoylphorbol (TP A)-induced erythema of mouse skin (Formukong et al., 1988). These reports, the very low toxicity (Rosenkrantz et al., 1981) and absence of psychotropic effects of CBD, led us to further investigate its immunosuppressive and antiinflammatory actions.

First we looked into some in vitro effects of CBD. As macrophages are the main producer of TNF during inflammation we examined the effect of CBD on TNF production by mouse macrophages after lipopolysaccharide (LPS) activation. At a dose of $6 \mathrm{mg} / \mathrm{ml} \mathrm{CBD} \mathrm{a} \mathrm{72 \%} \mathrm{suppression}$ ofTNF production was recorded (unpublished results). Similarly generation of nitric oxid (NO) by LPS-activated macrophages was markedly suppressed ( $88 \%$ with $4 \mathrm{mg} / \mathrm{ml}$ ) (unpublished results). Treatment of mouse granulocytes (stimulated with Zymosan) with $6 \mathrm{mg} / \mathrm{ml}$ CBD suppressed the production of reactive oxygen intermediates (ROI) by $45 \%$, if the cannabinoid was applied simultaneously with Zymosan, or by $92 \%$ if it was added $1 \mathrm{hr}$ before the activation (Malfait et al., 2000).

CBD also markedly suppressed Con-A induced in vitro proliferation of murine splenic lymphocytes. At a dose of $5 \mu \mathrm{g} / \mathrm{ml}$ a $90 \%$ suppression was noted (Malfait et al., 2000). In in vivo experiments high levels ofTNF were found in serum, $90 \mathrm{~min}-$ utes after LPS injection. When CBD was injected, either i.p. or s.c., together with LPS a marked suppression was noted ( 81 and $89 \%$ respectively).

Then we examined the effects of CBD in an animal model of arthritis murine collagen-induced arthritis (CIA) (Malfait et al., 2000). In this model DBA/1 mice are immunized with type II collagen in complete Freund's adjuvant. This type of collagen causes different types of arthritis depending on its source. Collagen from a bovine source causes classical acute arthritis, while murine collagen leads to chronic relapsing (homologous) CIA. The latter model has a clinical pattern, which resembles more closely the human disease than the classical acute (heterologous) CIA. Thus, the clinical score in the homologous model in mice typically alternates for several weeks. Overall, human arthritis is also chronic relapsing and progressive. Both humoral and cellular mechanisms are involved in the immune response to collagen-induced arthritis; the 
cellular response is $\mathrm{T}$ helper- 1 mediated. The clinical picture seen with this type of murine arthritis is a rapid onset of joint inflammation, leading to destruction of joint tissues and cartilage, and bone erosions. TNF is involved in the pathogenesis of CIA, as suppression of the inflammatory process by blocking TNF is an effective treatment. Indeed clinical trials in patients based on TNF suppression by various agents, such as anti-TNF monoclonal antibodies, have led to positive results.

In the classical (heterologous) CIA, treatment with CBD in mice started at the first clinical signs of the disease and was administered either i.p. daily for 10 days at doses of $2.5,5,10$ and $20 \mathrm{mg} / \mathrm{kg}$ or orally at higher doses, namely 10,25 and $50 \mathrm{mg} / \mathrm{kg}$ in olive oil. In the chronic (homologous) CIA treatment with CBD also started at the first clinical signs, but continued for 5 weeks either i.p. (doses of 5 or $10 \mathrm{mg} / \mathrm{kg}$ ) or orally (doses of $25 \mathrm{mg} / \mathrm{kg}$ ).

In both CIA models CBD had a dose-dependent therapeutic effect. In the classical model at $2.5 \mathrm{mg} / \mathrm{kg}$ no effect was noted, while the $5.0 \mathrm{mg} / \mathrm{kg}$ dose caused an optimal suppression of the disease. The higher doses (10 and $20 \mathrm{mg} / \mathrm{kg}$ ) had only a slight therapeutic effect. In the chronic model again we also noted better results with the $5 \mathrm{mg} / \mathrm{kg}$ dose than with the higher dose. This biphasic effect, as mentioned above, is quite typical for cannabinoids in various assays and is probably due to stimulation of Gs proteins at low doses and both Gs and Gi stimulaion at high doses, with inhibition presumably overwhelming the stimulation.

I.p. and oral administration of CBD had a comparable therapeutic effect on established arthritis in both models. However oral administration required higher doses $(25 \mathrm{mg} / \mathrm{kg})$ than those needed with i.p. doses $(5 \mathrm{mg} / \mathrm{kg}$ ).

Joints in the hind paws of mice with chronic homologous CIA treated with CBD were assessed and compared to those of control mice. In the chronic assay the best results in the i.p. group were noted with $5 \mathrm{mg} / \mathrm{kg}$. While $30 \%$ of the animals in the treated group retained normal hind feet, none of the control was without damage. About $90 \%$ of the hind feet in the control group showed arthritic changes, but only $60 \%$ of the group injected with CBD exhibited such changes, most of them being less damaged than those in the control group. In the group administered CBD orally, again, no animals in the control group survived without any damage, while $36 \%$ of the treated animals had no changes.
In several in vivo and in vitro assays we found that CBD exerts a potent immunosuppressive effect. Thus, synovial cells from arthritic mice spontaneously produce large amounts ofTNF when cultured in vitro. We compared the TNF production by the CBD treated mice (i.p., $5 \mathrm{mg} / \mathrm{kg}$, classical assay) with the controls on day 10 . The CBD treated-mice produced significantly less TNF than the control mice (Malfait et al., 2000). These data are of considerable importance as the synovium is the most critical site of cytokine production in arthritis.

Draining lymph node cells from CBD-treated arthritic DBA/1 mice when stimulated with collagen II in vitro suppressed lymphocyte proliferation and IFN- $\gamma$ production compared to controls.

The anti-inflammatory action of CBD is probably due to a combination of factors, the major ones of which are presumably the reduction of TNF in the synovium and the lower levels of IFN- $\gamma$ in lymph node cells. Immunosupression, especially of T-helper 1 response, is probably also of major importance.

As CBD has a very low toxicological profile and previously has been safely administered to humans (in trials connected with neurological diseases), its introduction in the clinic should be relatively facile.

\section{Cannabinoid acids}

\section{a. THC derived acids}

A major metabolic route of THC, both in the $\Delta^{9}$ - and the $\Delta^{8}$-THC series, is oxidation at C-11, initially leading to $11-0 \mathrm{H}-\mathrm{THC}$ and then to THC11-oic acid (Agurell et al., 1986; Mechoulam et al., 1973). Delta-8-THC-11-oic acid has anti-inflammatory properties (Burstein, 1989). As the 1, 1-dimethylheptyl homologs of THC are well known to be more potent in numerous bioassays (mostly in the CNS area) than the natural, pentyl constituents, we synthesized 1,1-dimethylheptyl- $\Delta^{8}$-THC-7oic acid (Burstein et al., 1992), which, under the names CT-3 or ajulemic acid, has been extensively evaluated for its anti-inflammatory properties (Burstein, 2001). It reduces the accumulation of leukocytes in a mouse model of acute inflammation, as well as the severity of adjuvant-induced polyarthritis in rats. Ajulemic acid also attenuated inflammation of joint tissue and damage to joint cartilage and bone was prevented (Burstein, 2001). 
Although these results are promising, the clinical use of ajulemic acid in chronic inflammation is doubtful. Ajulemic acid binds to both cannabinoid receptors, in particular to $\mathrm{CB}_{1}$ (Rhee et al., 1997). As it inhibits adenylyl cyclase much less than THC, we assumed that it may not have THC-like properties.

Unfortunately, it does show sedative effects in mice (Dajani et al., 1999) and in the specific cannabinoid assay in mice (the tetrad assay) it was as active as THC (Sumariwalla et al., 2004). As antiinflammatory drugs for chronic conditions are not necessarily administered in a hospital, but at home, it is conceivable that a drug with THC-like effects may not be readily approved. Hence we decided to synthesize and evaluate the comparable acid in the CBD series.

\section{b. CBD-DMH-7-oic acid}

The synthesis of this acid is described in Figure 3 (unpublished data). It is based on the specific epoxidation of the endocyclic double bond, leading to a single epoxide, which after a number of steps leads to the desired acid, code named HU-320.

First a psychotropic evaluation was undertaken (Sumariwalla et al., 2004). Female mice were injected i.p. with THC, ajulemic acid and HU-320 and tested in the standard cannabinoid (tetrad) assay, measuring ambulation, immotility, hypothermia and analgesia. Ajulemic acid and THC showed significant effects on CNS mediated functions. HU-320 was essentially inactive. Then we evaluated HU-320 in a number of in vitro and in vivo antiinflammatory models. Mice were immunized by a single intradermal injection of bovine collagen type II (CII). Arthritis appeared around day 21 post immuniztion. HU-320 was administered i.p. to the arthritic mice from day 1 of the appearance of the disease for 10 days at doses of $0.5,1$ and $2 \mathrm{mg} / \mathrm{kg}$. The paws of the mice were assessed for clinical signs (redness and swelling) following a standard scoring system. The clinical score of the animals receiving the drug ( 1 and $2 \mathrm{mg} / \mathrm{kg}$ ) was significantly better than that of the controls. Higher doses did not improve the results. The paw thickness of the treated mice was also significantly lower than that of the controls. Oral administration also improved the arthritis, however higher doses $(40 \mathrm{mg} / \mathrm{kg})$ were required. Histological examination indicated that the drug offered a significant degree of protection against joint damage. Reduction in synovial hyperplasia<smiles>C=C(C)C1CCC(C)=CC1c1c(O)cc(I)cc1O</smiles><smiles>[2H]c1cc(OC)c(OC)c(C2C=C(C)CCC2C(=C)C)c1</smiles><smiles>CC(C)=C1CCC2(C)OC2C1c1c(O)cc(I)cc1O</smiles>

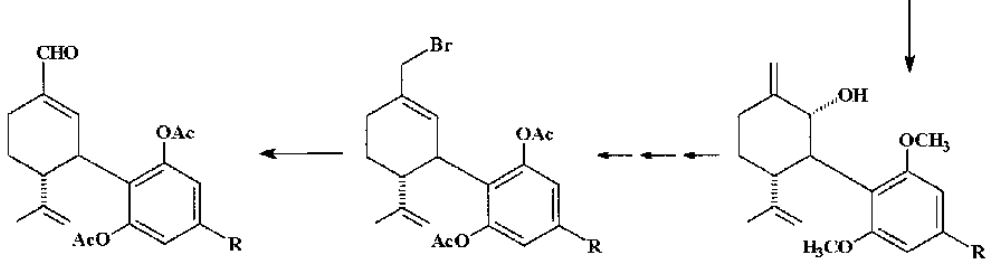<smiles>C=C(C)[C@@H]1CCC(C(=O)O)=CC1c1c(O)cc(Br)cc1O</smiles>

$\mathrm{R}=$ n-pentyl, CBD-7-oic acid

$\mathrm{R}=$ 1,1-dimethylhe ptyl, CBD-DMH-7-oic acid (HU-320) 
was also seen, and we noted a reduction in the numbers of infiltrating immune cells, such as monocytes, macrophages, neutrophiles and lymphocytes, as well as lowering of TNF levels induced by endotoxin challenge. We assume that the protection of the joint from cartilage loss and bone damage is due to this lowering of the influx of immune cells and their inactivation at the site of the disease (Sumariwalla et al., 2004).

In vitro observations paralleled the in vivo results. Thus we noted that in several cell types HU-320 down modulated the release of important mediators of arthritis, such as TNF, IFN- $\gamma$ and ROI, as seen previously with CBD. HU-320 also suppressed in vitro the proliferative response of lymph node cells primed with bovine CII, again suggesting that the drug exerts (in part at least) its anti-arthritic effects by suppressing cellular immune response to CII (Sumariwalla et al., 2004).

The resorcinol moiety confers anti-oxidant properties to numerous cannabinoids (Hampson et al., 1998). HU-320 likewise possesses such a moiety and indeed causes anti-oxidative effects, as noted by the lowering of ROI levels in vitro.

Each of the various immune effects seen with HU-320 presumably contributes to the overall powerful anti-rheumatic action. However the molecular mechanism of its action, like that of CBD, is still an enigma. Neither compound binds to the 2 known cannabinoid receptors. It is quite possible that both cannabidiol and HU-320 bind to one of the several yet unidentified novel cannabinoid receptors, which have been assumed to exist. Sancho et al. (2003) have shown that anandamide inhibits nuclear factor- $\kappa \mathrm{B}$ activation through a cannabinoid receptor-independent pathway. Are the compounds described now acting by the same route?

The toxicity of HU-320 has not yet been determined. However since CBD has extremely low toxicity in vivo, it is reasonable to assume that its metabolites (including the acid) are also nontoxic. As HU-320 is a homologue of this metabolite, its toxicity probably is also low.

\section{Conclusion}

Our recent work, described in part in this overview, indicates that the long known anti-inflammatory action of Cannabis sativa may be due in part to the non-psychotropic constituent canna- bidiol (and presumably also to its acidic metabolite). Both cannabidiol and a synthetic cannabidiol acid homolog (HU-320) are potent anti-inflammatory compounds in vitro and in vivo. Their clinical development may possibly add new drugs for rheumatoid arthritis.

\section{Acknowledgements}

The research in Jerusalem was supported by the Israel Science Foundation and the US National Institute of Drug Abuse.

\section{References}

Adams R (1941-1942) Marihuana Harvey Lect. 37: 168-197.

Agurell S, Halldin M, Lingren JE, Ohlsson A, Widman M, Gillespie H \& Hollister L (1986) Pharmacokinetics and metabolism of delta-1-tetrahydrocannabinol and other cannabinoids with emphasis on man. Pharmacol. Revs. 38: 21-43.

Brunner TF (1973) Marijuana in ancient Greece and Rome? The literary evidence Bull. Hist. Med. 47: 344-355.

Burstein S (1989) Delta-1-THC-7-oic Acid and Analgetic and Anti-inflammatory Agents. US Patent 4,847,290.

Burstein SH, Audette CA, Breuer A, Devane WA, Colodner S, Doyle SA \& Mechoulam R (1992) Synthetic nonpsychotropic cannabinoids with potent antiinflammatory, analgesic and leukocyte anti-adhesion activities. J. Med. Chem. 35: 3135-3141.

Burstein (2001) Ajulemic acid. Drugs Future 26: 342-345.

Burstein S (2001). Therapeutic potential of ajulemic acid (CT3), Cannabis and Cannabinoids. In Grotenherman F \& Russo E. (eds), Cannabis and Cannabinoids (pp. 381-388). New York: Haworth Press.

Cabral GA, Harmon KN \& Carlisle SJ (2001) Cannabinoidmediated inhibition of inducible nitric oxide production by rat microglial cells: Evidence for $\mathrm{CB}_{1}$ receptor participation. Adv. Exp. Med. Biol. 493: 207-214.

Campbell Thompson R (1949) A Dictionary of Assyrian Botany The British Academy, London, pp. 220-222.

Chopra IC \& Chopra RN (1957) The use of cannabis drugs in India. Bull. Narc. 9: 4-29.

Christison A (1851) On the natural history, action and uses of Indian hemp Monthly J. Med. Sci. 13: 26-45 and 177-121.

Dajani EZ, Larsen KR, Taylor J, Dajani NE, Shahwan TG, Neeleman SD, Taylor MS, Dayton MT \& Mir GN (1999) 1,1-dimethylheptyl-delta-8-tetrahydrocannabinol-11-oic acid: A novel orally effective cannabinoid with analgesic and antiinflammatory properties. J. Pharmacol. Exp. Ther. 291: 31-38.

Devane WA, Dysarz FA 3rd, Johnson MR, Melvin LS \& Howlett AC (1988) Determination and characterization of a cannabinoid receptor in rat brain. Mol. Pharmacol. 34: 605-613.

Devane WA, Breuer A, Sheskin T, Jarbe TUC, Eisen M \& Mechoulam R (1992a) A novel probe for the cannabinoid receptor. J. Med. Chem. 35: 2065-2069.

Devane WA, Hanus L, Breuer A, Pertwee RG, Stevenson LA, Griffm G, Gibson D, Mandelbaum A, Etinger A \& Mechoulam R (1992b) Isolation and structure of a brain 
constituent that binds to the cannabinoid receptor. Science 258: 1946-1949.

Dioscorides (1934) The Greek Herbal. In: Gunther RT, (ed) Oxford University Press, pp. 390-391, plant drawings 165 and 166 .

Donovan M (1845) On the physical and medicinal qualities of Indian hemp (Cannabis indica) Dublin J. Med. Sci. 26: 368402and 459-461.

Formukong EA, Evans AT \& Evans FJ (1988) Analgesic and anti-inflammatory activity of constituents of Cannabis sativa L. Inflammation 12: 361-371.

Fride E \& Mechoulam R (1993) Pharmacological activity of the cannabinoid agonist anandamide, a brain constituent. Eur. J. Pharmacol. 231: 313-314.

Gaoni Y \& Mechoulam R (1964) Isolation structure and partial synthesis of active constituent of hashish. J. Amer. Chern. Soc. 86: 1646-1647.

Hampson AJ, Grimaldi M, Axelrod J \& Wink D (1998) Cannabidiol and (-)delta(9)-tetrahydrocannabinol are neuroprotective antioxidants. Proc. Natl. Acad. Sci. (USA) 95: 8268-8273.

Howlett AC \& Fleming RM (1984) Cannabinoid inhibition of adenylate cyclase. Pharmacology of the response in neuroblastoma cell membranes. Mol. Pharmacol. 26: 532538

Howlett AC, Champion TM, Wilken GH \& Mechoulam R (1990) Stereochemical effects of 11-OH-delta-8-tetrahydrocannabinol-dimethylheptyl to inhibit adenylate cyclase and bind to the cannabinoid receptor. Neuropharmacol. 291: 161-165

Howlett AC, Barth F, Bonner TI, Cabral G, Casellas P, Devane WA, Felder CC, Herkenham M, Mackie K, Martin BR, Mechoulam R \& Pertwee RG (2002) Internation Union of Pharmacology. XXVII. Classification of cannabinoid receptors. Pharmacol. Rev. 54: 161-202.

Klein TW, Newton C, Larsen K, Lu L, Perkins I, Nong L \& Friedman H (2003) The cannabinoid system and immune modulation. J. Leukoc. Biol. 74: 486-489.

Lambert DM, Vandevoorde S, Jonsson KO \& Fowler CJ (2002) The palmitoylethanolamide family: A new class of anti-inflammatory agents? Curr. Med. Chem. 9: 663-674.

Malfait AM, Gallily R, Sumariwalla PF, Malik AS, Andreakos E, Mechoulam R \& Feldmann M (2000) The non-psychoactive cannabis-constituent cannabidiol is an oral antiarthritic therapeutic in murine collagen-induced arthritis. Proc. Natl. Acad. Sci. (USA) 97: 9561-9566.

Matsuda LA, Lolait SJ, Brownstein MJ, Young AC \& Bonner TI (1990) Structure of a cannabinoid receptor and functional expression of the cloned cDNA. Nature 346: 561-564.

Mechoulam R, Gaoni Y (1967) The absolute configuration of $\Delta^{1}$-tetrahydrocannabinol, the major active constituent of hashish. Tetrahededron Lett. 1109-1111.

Mechoulam R (1970) Marihuana chemistry Review. Science 168: 1159-1166.

Mechoulam R, Ben-Zvi Z, Agurell S, Nilsson IM, Nilsson JLG, Edery H \& Grunfeld Y (1973) Delta-6-tetrahydrocannabinol-7-oic acid, a urinary delta-6-THC metabolite - isolation and synthesis. Experientia 29: 1193-1195.

Mechoulam R. (1986). The Pharmacohistory of Cannabis sativa, Cannabinoids as Therapeutic Agents. In Mechoulam R (eds), Cannabinoids as Therapeutic Agents (pp. 1-19). Boca Raton Fl: CRC Press, Inc.

Mechoulam R, Feigenbaum JJ, Lander N, Segal M, Jarbe TUC, Hiltunen AJ \& Consroe P (1988) Enantiomeric cannabinoids: Stereospecificity of psychotropic activity. Experientia 44: 762-764.

Mechoulam R, Ben-Shabat S, Hanus L, Ligumsky M, Kaminski NE, Schatz AR, Gopher A, Almog S, Martin BR \& Compton DR (1995) Identification of a andogenous 2monoglyceride, present in canine gut, that binds to cannabinoid receptors. Biochem. Pharmacol. 50: 83-90.

Mechoulam R \& Ben-Shabat S (1999) From gan-zi-gun-nu to anandamide and 2-arachidonoyl-glycerol, the ongoing story of Cannabis. Nat. Prod. Rep. 16: 131-143.

Mechoulam R \& Hanus L. (2002) Cannabidiol: An overview of some chemical and pharmacological aspects. Part I: Chemical Aspects. Chem. Phys. Lipids 121: 35-43.

Mechoulam R, Parker LA \& Gallily R (2002) Cannabidiol: An overview of some pharmacological aspects. J. Clin. Pharmacol. 42: 11S-19S.

Melck D, Bisogno T, De-Petrocellis L, Beaulieu P, Rice AS \& Di Marzo V (2002) Cannabimimetic eicosanoids in cancer and inflammation: an update. Adv. Exp. Med. Biol. 507: 381-386.

Munro S, Thomas KL \& Abu-Shaar M (1993) Molecular characterization of a peripheral receptor for cannabinoids. Nature 365: 61-65.

O'Shaugnessy WB (1843) On the preparations of the Indian hemp, or Gunjah. Trans. Med. Physical Soc. Bengal, 421-461.

Rhee MH, Vogel Z, Barg J, Bayewitch M, Levy R, Hanus L, Breuer A \& Mechoulam R (1997) Cannabinol derivatives: Binding to cannabinoid receptors and inhibition of adenylylcyclase. J. Med. Chem. 40: 3228-3233.

Rosenkrantz H, Fleischman RW, Grant RJ (1981) Toxicity of short-term administration of cannabinoids to rhesus monkeys. Toxicol. Ap.

Roth MD, Baldwin GC \& Tashkin DP (2002) Effects of delta9-tetrahydrocannabinol on human immune function and host defense. Chem. Phys. Lipids 121: 229-239.

Russel Reynolds J (1890) Therapeutic uses and toxic effects of Cannabis indica Lancet 1: 637-638.

Sancho R, Calzado MA, Di Marzo V, Appendino G \& Munoz E (2003) Anandamide inhibits nuclear factor-KB activation through a cannabinoid receptor-independent pathway. Mol. Pharmacol. 63: 429-438.

Srivastava MD, Srivastava BI \& Brouhard B (1998) Delta9-tetrahydrocannabinol and cannabidiol alter cytokine production by human immune cells. Immunopharmacol. 40: 179-1885.

Sugiura T, Kondo S, Sukagawa A, Nakane S, Shinoda A, Itoh K, Yamashita A \& Waku K (1995) 2-Arachidonoylglycerol: a possible endogenous cannabinoid receptor ligand in brain. Biochem. Biophys. Res. Commun. 215: 89-97.

Sulcova E, Mechoulam R \& Fride E (1998) Biphasic effects ofanandamide. Pharmacol. Biochem. Behav. 59: 347-353.

Sumariwalla PF, Gallily R, Tchilibon S, Fride E, Mechoulam R, Feldmann M (2004) A novel synthetic non-psychoactive cannabinoid acid (HU-320) with anti-inflammatory properties in murine collagen-induced arthritis. Arthritis Rheumat. (in press).

Todd AR (1946) Hashish Experientia. 2: 55-60.

Turner CE, Elsohly MA \& Boeren EG (1980) Constituents of Cannabis sativa L. XVII. A review of the natural constituents. J. Nat. Prod. 43: 169-234.

Watzl B, Scuderi P \& Watson RR (1991) Marijuana components stimulate human peripheral blood mononuclear cell secretion of interferon-gamma and suppress interleukin-1 alpha in vitro. Int. J. Immunopharmacol. 13: 1091-1097. 